\title{
Synthesis, Structure, and Spectral Behavior of Donor-Acceptor Substituted Biphenyls ${ }^{1}$
}

\author{
Franz Effenberger, ${ }^{* 2 a}$ Wolfgang Agster, ${ }^{2 a}$ Peter Fischer, ${ }^{2 a}$ Kurt H. Jogun, ${ }^{2 a}$ John J. Stezowski, ${ }^{2 a}$ \\ Ewald Daltrozzo, ${ }^{2 \mathrm{~b}}$ and Georg Kollmannsberger-von Nell ${ }^{2 \mathrm{~b}}$
}

Institut für Organische Chemie der Universität Stuttgart, Pfaffenwaldring 55, D-7000 Stuttgart 80, West Germany, and Fakultät für Chemie der Universität Konstanz, Universitätsstraße 10, D-7750 Konstanz, West Germany

Received March 15, 1983

\begin{abstract}
Reaction of the activated halonitrobenzenes $2 \mathrm{a}-\mathbf{f}$ with the bis- and tris(dialkylamino)benzenes $1 \mathrm{a}-\mathrm{e}$ affords, via a direct nucleophilic substitution, the highly substituted biphenyls 3a-0; the lesser substituted biphenyls 5 and 6 were prepared by an Ullmann reaction. All these biphenyls are deeply colored; the dark red color can be assigned to an intramolecular charge transfer. A crystal structure determination was carried out for $2,4,6-$ tripyrrolidino-2 $2^{\prime} 4^{\prime}, 6^{\prime}$-trinitrobiphenyl (3a): space group $C 2 / c, a=16.071$ (2) $\AA, b=14.545$ (1) $\AA, c=20.177$ (2) $\AA, \beta=91.361(9)^{\circ}, Z=8$ (temperature $\approx 120 \mathrm{~K}$ ). The dihedral angle between the two arene rings was found to be only $52.5^{\circ}$, despite the four bulky substituents in the $0,0^{\prime}$-positions. With this far-from-orthogonal torsional angle about the biphenyl linkage, the strong intramolecular charge transfer from the $\pi$ system of the donor into the $\pi$ system of the acceptor arene becomes easily understandable. A PPP calculation with the torsional angles taken from the X-ray structure analysis satisfactorily reproduces the experimental absorption spectrum of 3a. The shift of the long-wavelength absorption between the individual biphenyls $3 a-0,5$, and 6 likewise is accounted for satisfactorily by the calculation; it depends primarily on the intrinsic donor strength of the different $\mathrm{NR}_{2}$ moieties (pyrrolidino $>$ dimethylamino $>$ piperidino $>$ morpholino). The ${ }^{1} \mathrm{H}$ NMR spectra (in dilute solution) likewise mirror this gradation in $\mathrm{NR}_{2}$ donor capacity; they also show that steric hindrance at the biphenyl linkage is mainly the result of interaction between the o-dialkylamino groups and the $C_{6}$ skeleton of the acceptor arene. This is borne out by the crystal structure analysis.
\end{abstract}

In a preliminary paper ${ }^{3}$ we have reported the facile synthesis of donor-acceptor substituted biphenyls via nucleophilic aromatic substitution of activated haloarenes by electron-rich aminobenzenes. These biphenyls are isolated as lustrous crystals which are surprisingly deep red to almost black. Because of the bulky substituents in $o-$ and $o^{\prime}$-positions, one would expect a nearly orthogonal orientation, and thus negligible mesomeric interaction, of the two phenyl rings. The dark red color had to be attributed to intramolecular charge-transfer processes, though, on the basis of the spectroscopic data and of calculations. ${ }^{4}$

It seemed desirable to test the scope of the new biphenyl synthesis, beyond those examples already reported, ${ }^{3,4}$ with respect to the reactivity limits for the amino- as well as the halobenzene components. This would allow for a systematic substituent variation in both the donor and acceptor moieties of the biphenyls, a prerequisite for a definitive study of the low-energy absorption, and thence of the bonding in these compounds.

We now report the preparation of a fairly wide range of donor-acceptor substituted biphenyls, together with the crystal structure analysis of one representative member, 2,4,6-tripyrrolidino- $2^{\prime}, 4^{\prime}, 6^{\prime}$-trinitrobiphenyl. The ${ }^{1} \mathrm{H}$ NMR spectra are discussed in terms of ground-state solution conformation, and the nature of the long-wavelength electronic transition is established unequivocally on the basis of SCF-CI calculations.

\section{Synthesis of Donor-Acceptor Substituted Biphenyls via Nucleophilic Aromatic Substitution}

A decisive factor in the formation of the biphenyls 3 via this synthetic route is the aryl carbon nucleophilicity of

(1) Aminobenzenes. 16. For part 15 see: Effenberger, F.; Menzel, P.; Seufert, W. Chem. Ber. 1979, 112, 1660-1669.

(2) (a) Universität Stuttgart. (b) Universität Konstanz.

(3) Effenberger, F.; Nagel, K.; Agster, W. Angew. Chem. 1971, 83, 619. Angew. Chem., Int. Ed. Engl. 1971, 10, 566.

(4) Daltrozzo, E.; Effenberger, F.; Fischer, P. Angew. Chem. 1971, 83, 621-622. Angew. Chem., Int. Ed. Engl. 1971, 10, 567-568.
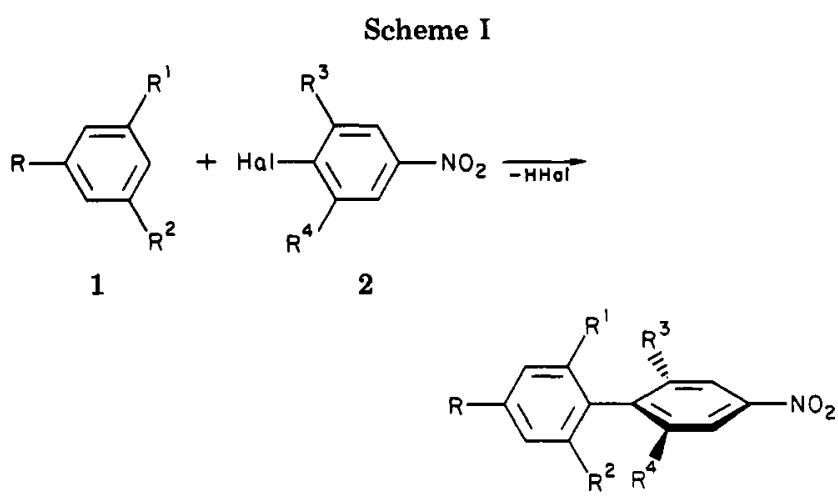

3

the aminobenzene substrate 1 ; it strongly depends on number and relative positions of the amino substituents on the ring as well as on the nature of the $\mathrm{NR}_{2}$ moieties. We have demonstrated in the course of extensive investigations on mono-, di- and triaminobenzenes ${ }^{5}$ that the mesomeric interaction of amino groups with an aromatic $\pi$ system, and concomitantly the aryl-C nucleophilicity, decreases in the order pyrrolidino $>$ dimethylamino $>$ piperidino $>$ morpholino. Meta orientation (rather than ortho or para) of the individual $\mathrm{NR}_{2}$ substituents in polyaminobenzenes provides the best stabilization of the cationic reaction intermediate as substituent effects are approximately additive for meta derivatives. ${ }^{6}$ In the case of the second reactant, the 4-halonitrobenzenes 2 , reactivity parameters are known for a number of additional substituents. ${ }^{7}$

The limit for a polar formation of a biphenyl linkage, set by the relative reactivity of the components 1 and 2 , should easily be established with the help of these data.

(5) Effenberger, F.; Fischer, P.; Schoeller, W. W.; Stohrer, W. D. Tetrahedron 1978, 34, 2409-2417.

(6) Jaffe, H. H. Chem. Rev. 1953, 53, 191-261.

(7) (a) Miller, J.; Parker, A. J. Aust. J. Chem. 1958, 11, 302-308. (b) Berliner, E.; Monack, L. C. J. Am. Chem. Soc. 1952, 74, 1574-1579. 
Table I. Biphenyls 3 from Aminobenzenes 1 and 4-Halonitrobenzenes $2^{e}$

\begin{tabular}{|c|c|c|c|c|c|c|c|c|c|}
\hline \multicolumn{3}{|c|}{ aminobenzene $^{a}$} & \multicolumn{4}{|c|}{ 4-halonitrobenzene } & \multirow[b]{2}{*}{ biphenyl $^{a}$} & \multirow[b]{2}{*}{ yield, \% } & \multirow[b]{2}{*}{$\mathrm{mp},{ }^{\circ} \mathrm{C}$} \\
\hline no. & $\mathrm{R}, \mathrm{R}^{1}$ & $\mathrm{R}^{2}$ & no. & $\mathrm{Hal}$ & $\mathrm{R}^{3}$ & $\overline{\mathrm{R}^{4}}$ & & & \\
\hline $\begin{array}{l}1 \mathrm{a} \\
1 \mathrm{~b}\end{array}$ & $\mathrm{pyr}_{\mathrm{NMe}}$ & $\begin{array}{l}\text { pyr } \\
\mathrm{NMe}_{2}\end{array}$ & $\begin{array}{l}2 \mathrm{a} \\
2 \mathrm{a}\end{array}$ & $\mathrm{Cl}$ & $\mathrm{NO}_{2}$ & $\mathrm{NO}_{2}$ & $\begin{array}{l}\text { 2,4,6-tripyrrolidino-2', } 4^{\prime}, 6^{\prime} \text {-trinitro (3a) } \\
2,4,6 \text {-tris(dimethylamino)- } \\
2^{\prime}, 4^{\prime}, 6^{\prime} \text {-trinitro (3b) }\end{array}$ & $\begin{array}{l}76 \\
60^{b}\end{array}$ & $\begin{array}{l}174-176 \\
258\end{array}$ \\
\hline $1 \mathrm{c}$ & pip & pip & $2 a$ & & & & $2,4,6$-tripiperidino-2', $4^{\prime}, 6^{\prime}$-trinitro $(3 \mathrm{c})$ & 71 & 223 \\
\hline $1 \mathrm{~d}$ & mor & mor & $2 a$ & & & & $2,4,6$-trimorpholino- $2^{\prime}, 4^{\prime}, 6^{\prime}$-trinitro (3d) & 68 & 254 \\
\hline $1 \mathrm{e}$ & pyr & $\mathrm{H}$ & $2 a$ & & & & 2,4-dipyrrolidino-2', $4^{\prime}, 6^{\prime}$-trinitro (3e) & 74 & 184 \\
\hline $\mathbf{1 f}$ & pip & $\mathrm{H}$ & $2 a$ & & & & 2,4-dipiperidino-2', $4^{\prime}, 6^{\prime}$-trinitro (3f) & $65^{c}$ & 178 \\
\hline $1 \mathrm{a}$ & & & $2 b$ & $\mathrm{Cl}$ & $\mathrm{H}$ & $\mathrm{NO}$ & $2,4,6$-tripyrrolidino- $2^{\prime}, 4^{\prime}$-dinitro $(3 \mathrm{~g})$ & 74 & 184 \\
\hline $1 \mathbf{a}$ & & & $2 \mathbf{c}^{\prime}$ & $\mathrm{F}$ & $\mathrm{H}$ & & $2,4,6$-tripyrrolidino- 4 -nitro $(3 \mathrm{~h})$ & $13^{d}$ & 236 \\
\hline $1 \mathrm{a}$ & & & $2 \mathrm{~d}$ & $\mathrm{Cl}$ & $\mathrm{H}$ & $\mathrm{CN}$ & $\begin{array}{l}2,4,6 \text {-tripyrrolidino- } 2^{\prime} \text {-cyano- } 4^{\prime}- \\
\text { nitro }(3 \mathrm{i})\end{array}$ & 62 & $211-212$ \\
\hline $1 \mathbf{a}$ & & & $2 \mathbf{e}$ & $\mathrm{Cl}$ & $\mathrm{H}$ & $\mathrm{CO}_{2} \mathrm{Me}$ & 2,4,6-tripyrrolidino-2' & 47 & 232 \\
\hline $\mathbf{1 a}$ & & & $\mathbf{2} \mathbf{e}^{\prime}$ & $F$ & & $\mathrm{CO}_{2} \mathrm{Me}$ & (methoxycarbonyl)-4'-nitro (3k) & 86 & \\
\hline $1 \mathbf{a}$ & & & $2 f$ & $\mathrm{Cl}$ & $\mathrm{CO}_{2} \mathrm{Me}$ & $\mathrm{CO}_{2} \mathrm{Me}$ & $\begin{array}{l}\text { 2,4,6-tripyrrolidino-2',6' - bis(methoxy- } \\
\text { carbonyl)-4' -nitro }(31)\end{array}$ & 78 & 213 \\
\hline $1 \mathbf{a}$ & & & $2 \mathrm{~g}$ & $\mathrm{Cl}$ & $\mathrm{NO}_{2}$ & $\mathrm{CO}_{2} \mathrm{Me}$ & $\begin{array}{l}2,4,6 \text {-tripyrrolidino- } 2^{\prime}-(\text { methoxy- } \\
\text { carbonyl)- } 4^{\prime}, 6^{\prime} \text {-dinitro }(3 \mathrm{~m})\end{array}$ & 18 & 186 \\
\hline $1 \mathrm{a}$ & & & $2 \hat{\mathrm{h}}$ & $\mathrm{Cl}$ & $\mathrm{NO}_{2}$ & $\mathrm{CN}$ & $\begin{array}{l}\text { 2,4,6-tripyrrolidino-2'-cyano- } \\
4^{\prime}, 6^{\prime} \text {-dinitro }(3 n)\end{array}$ & 26 & dec \\
\hline $1 \mathrm{e}$ & & & $2 \mathrm{~g}$ & $\mathrm{Cl}$ & $\mathrm{NO}_{2}$ & $\mathrm{CO}_{2} \mathrm{Me}$ & $\begin{array}{l}\text { 2,4-dipyrrolidino-2 -(methoxy- } \\
\text { carbonyl })-4^{\prime}, 6^{\prime} \text {-dinitro }(3 o)\end{array}$ & 84 & 148 \\
\hline
\end{tabular}

${ }^{a}$ Pyr $=$ pyrrolidino, $\mathrm{NMe}_{2}=$ dimethylamino, pip = piperidino, mor $=$ morpholino. ${ }^{b} 10-\mathrm{min}$ reflux. ${ }^{c} 12-\mathrm{h}$ reflux.

${ }^{d}$ Reaction carried out in a sealed tube $\left(20 \mathrm{~h}\right.$ at $\left.120^{\circ} \mathrm{C}\right)$. ${ }^{e}$ Reflux $(3-4 \mathrm{~h})$ in $1: 1$ chloroform/ethanol.

The aminobenzenes 1 were therefore brought to reaction with the halobenzenes 2 (Scheme I) in the order of decreasing reactivity; the reactions were carried out in solution ( $4 \mathrm{~h}$ reflux in an ethanol/chloroform mixture) or neat, depending on the respective reactivity of 2 , or in some cases in sealed tubes at elevated temperature (see Table I). Picryl chloride (2a), the most reactive of the haloarenes employed, smoothly reacts with all triaminobenzenes $1 \mathrm{a}-\mathrm{d}$ to give the corresponding biphenyls $3 \mathbf{a}-\mathbf{d}$ under our standard conditions (see Table I). In the reactions of $2 \mathbf{a}$ with dipyrrolidino- and dipiperidinobenzene (le,f), the less reactive $1 f$ required 4 times the reflux time for a biphenyl yield comparable to that with 1e. Finally, all attempts failed to obtain biphenyls from $2 \mathbf{a}$ and mono(dialkylamino)benzenes.

The less activated chlorodinitrobenzene $\mathbf{2 b}$ readily forms a biphenyl derivative (3g) with tripyrrolidinobenzene (1a), though not, even under the most drastic conditions, with tripiperidinobenzene (1b). No biphenyl is obtained from $1 \mathrm{a}$ and 4-chloronitrobenzene (2c); with 4-fluoronitrobenzene $\left(2 c^{\prime}\right)$, the biphenyl $\mathbf{3 h}$ is formed only in poor yield and under severe conditions. $1 \mathrm{a}$ and 4-fluoro- and 4chloro-3-(methoxycarbonyl)nitrobenzene $\left(2 \mathbf{e}^{\prime}, \mathbf{e}\right)$ give 2,4,6-tripyrrolidino-2'-(methoxycarbonyl)-4'-nitrobiphenyl (3k) in $86 \%$ and $47 \%$ yields, respectively, under standard conditions (Table I). The evidently higher reactivity of the fluoro derivatives suggests that addition is the ratelimiting step, at least in the slower of these substitution processes, as in other, straightforward $S_{N} A r$ reactions.

\section{Donor-Acceptor Substituted Biphenyls via Ullmann Reaction}

For the analysis of the electronic spectra, we also needed some donor-acceptor substituted biphenyls with less steric hindrance about the central $\mathrm{C}-\mathrm{C}$ bond, i.e., with unsubstituted ortho positions in either of the two phenyl rings. As described above, the limits imposed upon the activation of the reactants 1 and 2 for a successful direct nucleophilic substitution allowed the preparation only of $2,4,6$-tripyrrolidino-4'-nitrobiphenyl (3h). 4-(Dialkylamino)$2^{\prime}, 4^{\prime}, 6^{\prime}$-trinitrobiphenyls 5 could be synthesized, though with rather moderate yields, via an Ullmann reaction from suitable 4-iodoaminobenzenes 4 and 1,3,5-trinitrobenzene

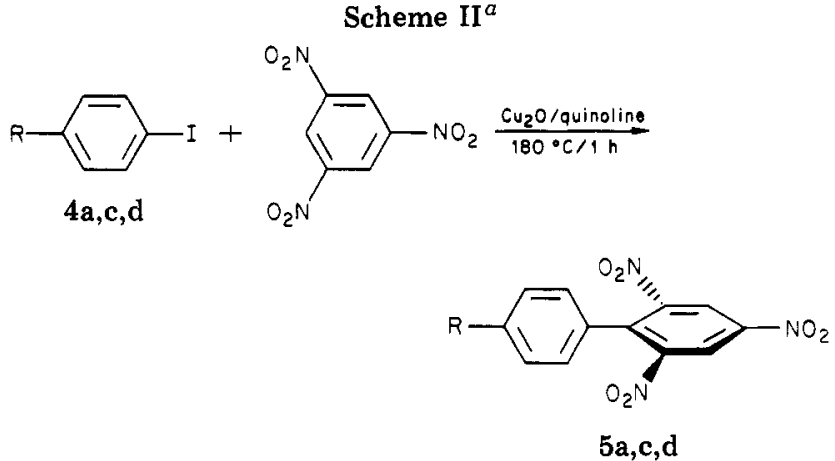

${ }^{a} \mathrm{a}, \mathrm{R}=$ pyr;, $\mathrm{R}=$ pip; $\mathrm{d}, \mathrm{R}=$ mor.

Scheme III $^{a}$

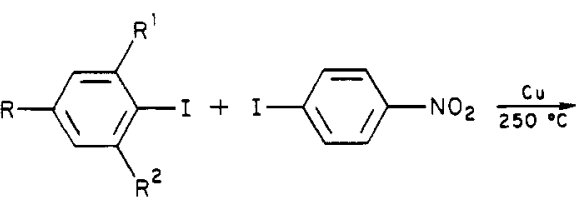

$6 \mathrm{c}, \mathrm{d}$

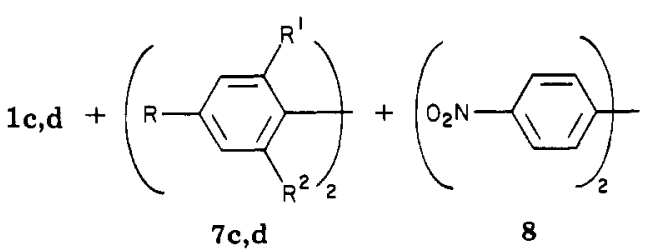

${ }^{a} c, R=R^{1}=R^{2}=\operatorname{pip} ; d, R=R^{1}=R^{2}=$ mor.

(Scheme II) in the presence of $\mathrm{Cu}_{2} \mathrm{O}$ /quinoline. ${ }^{8}$ The iodoaminobenzenes $\mathbf{4 a}, \mathrm{c}$ were obtained by $\mathrm{N}$-alkylation of 4-iodoaniline with 1,4-dibromobutane and 1,5-dibromopentane, respectively; $4 \mathrm{~d}$ was prepared by direct iodination of morpholinobenzene with $\mathrm{I}_{2}$.

The synthesis of 2,4,6-triamino-4'-nitrobiphenyls such as $\mathbf{3 h}$ failed under the conditions of an Ullmann reaction.

(8) (a) Björklund, C.; Nilsson, M. Acta Chem. Scand. 1968, 22 2581-2584. (b) Fanta, P. E. Synthesis 1974, 1, 9-21. 
Reaction of 2,4,6-tripiperidino- and 2,4,6-trimorpholinoiodobenzene $(\mathbf{6 c}, \mathbf{d})$, respectively, with 4-iodonitrobenzene in the presence of metallic $\mathrm{Cu}$ yielded only the symmetrical hexamino- and dinitrobiphenyls 7c,d and 8 (Scheme III), apart from dehalogenated triaminobenzenes $\mathbf{1 c}, \mathbf{d}$. With $\mathrm{Cu}_{2} \mathrm{O}$ /quinoline, only 1 and 7 , but no trace of 8 , could be isolated. Attempts to prepare 2,4,6-tripiperidino-4'nitrobiphenyl via a Gomberg reaction from tripiperidinobenzene $1 \mathrm{c}$ and $p$-nitrophenyldiazonium salts failed in both homogeneous and heterogeneous phases.

\section{${ }^{1} \mathrm{H}$ NMR Spectra}

Since NMR spectra reflect upon molecules in a state which is practically unperturbed energetically, ${ }^{1} \mathrm{H}$ and ${ }^{13} \mathrm{C}$ NMR of the biphenyls 3 and 5 should afford some insight into the effective charge transfer from the amino- (donor) to the nitrophenyl (acceptor) unit in the molecular ground state. Decomposition of the biphenyls 3 thwarted all attempts to obtain satisfactory ${ }^{13} \mathrm{C}$ spectra which would have provided a much more powerful probe for changes in $\pi$ charge density. ${ }^{1} \mathrm{H}$ spectra were run with $0.1 \mathrm{M}$ solutions to minimize solute-solute interactions. The extremely constant residual solvent proton resonances $\left(\mathrm{CHCl}_{3}\right.$, $\mathrm{CD}_{2} \mathrm{HCN}$ ) indicate the absence of bulk medium effects; the chemical shift values in Table II may consequently be considered to be significant to at least $\pm 0.003 \mathrm{ppm}$.

For the 4-(dialkylamino)-2', $4^{\prime}, 6^{\prime}$-trinitrobiphenyls 5a,c,d, the high-field shift of the $3^{\prime}, 5^{\prime}$-protons in the acceptor moiety (both in $\mathrm{CDCl}_{3}$ and $\mathrm{CD}_{3} \mathrm{CN}$; see Table II) clearly mirrors the increasing donor potential of the individual $\mathrm{NR}_{2}$ moieties (mor $<$ pip $<\mathrm{pyr}^{5}$ ). Introduction of two further dialkylamino donors in positions 2 and 6 of the donor arene does not alter this trend, $\delta\left(3^{\prime}, 5^{\prime}-\mathrm{H}\right)$ again moving upfield in the expected order: $\mathbf{3 d}$ (mor) $\rightarrow \mathbf{3 c}$ (pip) $\rightarrow 3 \mathbf{b}\left(\mathrm{NMe}_{2}\right) \rightarrow 3 \mathrm{a}$ (pyr). The absolute values, however, are not shifted to substantially higher field, as expected from the presence of three donor functions, but rather to slightly lower field. The effect is small for the pyrrolidino but clearly pronounced for the piperidino and morpholino derivatives $(\Delta \delta=0.20 \mathrm{ppm})$. Since these six-membered cyclic amines are nonplanar and thus bulkier, the (unexpected) downfield shift is very likely sterically induced. It cannot be distinguished, though, whether this is due to increased torsion about the biphenyl linkage (and a concomitant decrease in charge transfer) or simply to a larger twist of the $0-\mathrm{NO}_{2}$ functions relative to the plane of the acceptor arene which would result in a change in the anisotropy field at the two meta protons $3^{\prime}, 5^{\prime}-\mathrm{H}$.

The assumption that steric effects are responsible for the observed deshielding is supported by the fact that it is 3-4 times larger in the $\mathrm{H}$-donor solvent $\mathrm{CDCl}_{3}$ than in $\mathrm{CD}_{3} \mathrm{CN}$; solvation of the $\mathrm{NR}_{2}$ lone pairs and/or the $\mathrm{N} \rightarrow \mathrm{O}$ dipoles of the $\mathrm{NO}_{2}$ groups is expected to be much stronger for $\mathrm{D}-\mathrm{CCl}_{3}$, thus increasing the effective size of the respective substituents. That steric factors are indeed operative (which in turn are much more stringent for the piperidino than for the pyrrolidino group) receives additional confirmation from the following: relative to $\mathbf{5 a}$, $3^{\prime}, 5^{\prime}-\mathrm{H}$ are shifted downfield by only $0.01 \mathrm{ppm}$ in the 2,4-dipyrrolidino derivative $3 \mathrm{e}$ and by $0.11 \mathrm{ppm}$ in the 2,4,6-tripyrrolidino derivative 3a. In the piperidino series, on the other hand, the first and second o-pip functions shift $\delta\left(3^{\prime}, 5^{\prime}-\mathrm{H}\right)$ downfield by 0.08 and $0.13 \mathrm{ppm}$ each. These steric effects are clearly mirrored in the electronic spectra, the bathochromic shift of the long-wavelength absorption appearing much attenuated upon introduction of the third $\mathrm{NR}_{2}$ group (see Table III, Figure 4).

The 3,5-H signals of the tripyrrolidinobiphenyls with one, two, and three $\mathrm{NO}_{2}$ groups in the acceptor unit, in contrast, respond to the increasing acceptor potential of the nitrophenyl ring in a straightforward manner, moving downfield by $0.04 \mathrm{ppm}$ each from $3 \mathrm{~h}$ to $3 \mathrm{~g}$ and from $3 \mathrm{~g}$ to $3 \mathbf{a}$. The linear gradation indicates that in this series the two $0-\mathrm{NO}_{2}$ functions do not contribute significantly to the steric hindrance about the biphenyl linkage. This also is borne out by the fairly monotonic bathochromic shift of the long-wavelength absorption in the series $3 \mathbf{h ~} \rightarrow$ $\mathbf{3 g} \rightarrow \mathbf{3 a}$ (see Table III, Figure 3). The decisive factor for the actual torsion about the $\mathrm{C}-1 / \mathrm{C}-1^{\prime}$ bond, and thus the effective ground-state charge transfer, seems to be the steric interaction between the dialkylamino groups in 2and 6-positions of the donor and the $\mathrm{C}_{6}$ skeleton of the acceptor unit. This observation is supported by the crystal structure analyses of $\mathbf{3 a}$ and of methyltripyrrolidinobenzene (see below).

In all our biaryls, the $\mathrm{N}-\mathrm{CH}_{2}$ protons of the amino functions ortho to the biaryl linkage are shifted upfield by more than $0.5 \mathrm{ppm}$ relative to those of the respective para functions (see Table II). This cannot be due to special mesomeric demand on the $p-\mathrm{NR}_{2}$ moiety since the chemical shift difference is more than 20 times the $\Delta \delta$ value for the aryl protons and since the $\beta-\mathrm{CH}_{2}$ protons of the $o$ dialkylamino groups likewise experience 0.3 -ppm high-field shifts. Rather, the $o-\mathrm{NR}_{2}$ groups must be assumed to lie well within the diamagnetic screening cone of the nitrophenyl ring. The even larger upfield shift $(-0.75 \mathrm{ppm})$ for the $\alpha$-piperidino signals shows that these protons intrude still deeper into the region of the anisotropic ring current; this is not unreasonable on consideration of the chair conformation of the piperidino substituent, in contrast to the quasi-planar structure of the pyrrolidino ring. The $p-\mathrm{N}-\mathrm{CH}_{2}$ signal remains unchanged within the series mono-, di-, trinitrotripyrrolidinobiphenyl $(\mathbf{3 h} \rightarrow \mathbf{3 g} \rightarrow \mathbf{3 a}$ ), i.e., the $p-\alpha-\mathrm{CH}_{2}$ protons do not feel the electron demand of the nitroarene moiety to any significant degree. The $o-\mathrm{N}-\mathrm{CH}_{2}$ signals are shifted to lower field by only $0.05 \mathrm{ppm}$ in this series, due probably to some anisotropic deshielding by the $\mathrm{NO}_{2}$ groups. The small shift rules out appreciable steric interaction between nitro and dialkylamino functions in positions ortho to the biphenyl linkage, respectively.

The $p-\mathrm{N}-\mathrm{CH}_{2}$ resonance again is not affected in the series mono-, di-, tripyrrolidinotrinitrobiphenyl $(5 \mathbf{a} \rightarrow \mathbf{3 e}$ $\rightarrow 3 \mathrm{a}$ ); the $\mathrm{o}-\mathrm{N}-\mathrm{CH}_{2}$ signal in 3 , though, appears deshielded by $0.13 \mathrm{ppm}$ relative to $3 \mathrm{a}$. This might be rationalized in terms of an increase in the $\mathrm{C}^{1}-\mathrm{C}^{1^{\prime}}-\mathrm{C}^{2^{\prime}}$ bond angle, removing the $o$-pyrrolidino function somewhat from the screening region of the nitrophenyl ring.

\section{Electronic Spectra}

The dark red color of all our donor-acceptor substituted biphenyls is due to a specific, long-wavelength absorption; its energy depends, as the compilation of $\tilde{\nu}_{\max }$ values in Table III demonstrates, on both the kind and number of the individual substituents. For the biphenyls 3 , the high $0,0^{\prime}$-substitution suggests an orthogonal orientation of the two arene systems (characterized by a torsional angle $\theta$ of $\left.90^{\circ}\right)$. Three different intramolecular charge-transfer processes (i-iii) had originally been considered ${ }^{4}$ for the explanation of the long-wavelength absorption in this conformation. None of these, however, stands a more detailed, quantitative inspection.

(i) The first process was interaction of the "lone" electron pairs of both $o$-amino nitrogens with the $\mathrm{p}_{z}$ atomic functions in the 1'-position and, to a lesser degree, with those in positions $2^{\prime}$ and $6^{\prime}$, requiring a full twist between the donor nitrogen $\mathrm{p}$ orbital and the aminobenzene $\pi$ system (torsional angle $\Phi=90^{\circ}$ ). Numerical analysis shows that the overlap integral amounts to only $0.052 \beta_{0}$ for $\mathrm{sp}^{2}$ and 
Table II. 'H Chemical Shifts of Dialkylamino ${ }^{a}$ Nitro Biphenyls 3 and $5\left(0.1 \mathrm{M} \text { in } \mathrm{CDCl}_{3} / \mathrm{CD}_{3} \mathrm{CN}, 25{ }^{\circ} \mathrm{C}\right)^{b}$

\begin{tabular}{|c|c|c|c|c|c|c|c|c|c|c|c|}
\hline \multirow[b]{3}{*}{ compd } & \multirow[b]{3}{*}{$\mathbf{R}$} & \multirow[b]{3}{*}{$\mathrm{R}^{3}$} & \multirow[b]{3}{*}{$\mathbf{R}^{2}$} & \multirow[b]{3}{*}{$\mathbf{R}^{3}$} & \multirow[b]{3}{*}{$\mathrm{R}^{4}$} & \multirow[b]{3}{*}{$3^{\prime}, 5^{\prime}-\mathrm{H}^{c}$} & \multirow[b]{3}{*}{$3,5-\mathrm{H}^{c}$} & mical shift, & $\left.\mathrm{Me}_{4} \mathrm{Si}\right)$ & & \\
\hline & & & & & & & & \multicolumn{2}{|c|}{$\mathbf{R}^{1}, \mathbf{R}^{2}$ (ortho) ${ }^{d}$} & \multicolumn{2}{|c|}{$\mathrm{R}$ (para) $)^{d}$} \\
\hline & & & & & & & & $N-\mathrm{CH}_{2}(\alpha)$ & $\mathrm{CH}_{2}(\beta)$ & $N-\mathrm{CH}_{2}(\alpha)$ & $\mathrm{CH}_{2}(\beta)$ \\
\hline $\begin{array}{l}3 \mathbf{a} \\
\mathbf{3 b}\end{array}$ & $\begin{array}{l}\text { pyr } \\
\text { NMe }\end{array}$ & $\begin{array}{l}\text { pyr } \\
\text { NMe }\end{array}$ & $\begin{array}{l}\text { pyr } \\
\mathrm{NMe}\end{array}$ & $\begin{array}{l}\mathrm{NO}_{2} \\
\mathrm{NO}\end{array}$ & $\begin{array}{l}\mathrm{NO}_{2} \\
\mathrm{NO}\end{array}$ & $\begin{array}{l}8.773 / 8.742 \\
8.817\end{array}$ & $\begin{array}{l}6.013 / 6.021 \\
6.205\end{array}$ & $\begin{array}{l}2.78_{0} / 2.71_{0} \\
2.58_{0}\end{array}$ & $1.72_{0} / 1.66_{0}$ & $\begin{array}{l}3.34_{0} / 3.31_{0} \\
3.04_{0}\end{array}$ & $2.01_{5} / 1.99_{5}$ \\
\hline $3 c$ & pip & pip & pip & $\mathrm{NO}_{2}$ & $\mathrm{NO}_{2}$ & $8.901 / 8.858$ & $6.407 / 6.424$ & $2.61_{5} / 2.59_{5}$ & $1.34_{5} / 1.32_{5}$ & $3.25_{5} / 3.25_{5}$ & $1.63_{5} / 1.64_{0}$ \\
\hline $\begin{array}{l}30 \\
3 e\end{array}$ & $\begin{array}{l}\text { mor } \\
\text { pyr }\end{array}$ & $\begin{array}{l}\text { mor } \\
\text { pyr }\end{array}$ & $\begin{array}{l}\text { mor } \\
\mathrm{H}\end{array}$ & $\mathrm{NO}_{2}$ & $\mathrm{NO}_{2}$ & $\begin{array}{l}8.921 / 8.825 \\
8.679 / 8.731\end{array}$ & $\begin{array}{l}6.056 / 6.083(3-\mathrm{H}) \\
6.192 / 6.180(5-\mathrm{H}) \\
6.829(6-\mathrm{H})\end{array}$ & $\begin{array}{l}2.6 \\
2.91_{5} / 2.63_{0} \\
\end{array}$ & $\begin{array}{l}3.48_{0} / 3.39_{0} \\
1.76_{5} / 1.72_{0}\end{array}$ & $\begin{array}{l}3.20_{0} / 3.24_{0} \\
3.33_{5} / 3.30_{0}\end{array}$ & $\begin{array}{l}3.88_{5} / 5.19_{0} \\
2.01_{0} / 1.99_{s}\end{array}$ \\
\hline $3 f$ & pip & pip & $\mathbf{H}$ & $\mathrm{NO}_{2}$ & $\mathrm{NO}_{2}$ & $8.774 / 8.827$ & $\begin{array}{l}\text { 6.611/6.717(3-H) } \\
\quad 6.632 / 6.727(5-\mathrm{H}) \\
6.908(6-\mathrm{H})\end{array}$ & $2.71_{0} / 2.69_{3}$ & $1.39_{0} / 1.36_{5}$ & $3.29_{0} / 3.31_{0}$ & $1.66_{0} / 1.66_{0}$ \\
\hline $3 g$ & pyr & pyr & pyr & $\mathrm{NO}_{2}$ & $\mathbf{H}$ & $\begin{array}{l}8.692\left(3^{\prime}-\mathrm{H}\right) \\
8.296\left(5^{\prime}-\mathrm{H}\right) \\
7.700\left(6^{\prime}-\mathrm{H}\right)\end{array}$ & $5.975 / 5.974$ & $2.73_{0} / 2.68_{5}$ & $1.69_{0} / 1.64_{5}$ & $3.33_{5} / 3.29_{5}$ & $1.99_{5}$ \\
\hline $3 \mathbf{h}$ & pyr & pyr & pyr & $\mathbf{H}$ & $\mathbf{H}$ & $\begin{array}{c}7.594\left(2^{\prime}-\mathrm{H}\right) \\
8.138\left(3^{\prime}-\mathrm{H}\right)\end{array}$ & 5.942 & $2.72_{0}$ & $1.63_{s}$ & $3.34_{5}$ & $1.99_{5}$ \\
\hline $\mathbf{5 a}$ & $\mathrm{H}$ & pyr & $\mathrm{H}$ & $\mathrm{NO}_{2}$ & $\mathrm{NO}_{2}$ & $8.668 / 8.774$ & $\begin{array}{l}7.062(2-\mathrm{H}) \\
\quad 6.573 / 6.614(3-\mathrm{H})\end{array}$ & & & $3.33_{0} / 3.30_{5}$ & $2.03_{0} / 2.00_{5}$ \\
\hline $5 c$ & $\mathbf{H}$ & pip & $\mathrm{H}$ & $\mathrm{NO}_{2}$ & $\mathrm{NO}_{2}$ & $8.695 / 8.801$ & $\begin{array}{l}7.079(2-\mathrm{H}) \\
6.915 / 6.969(3-\mathrm{H})\end{array}$ & & & $3.29_{5} / 3.28_{5}$ & $1.66_{5} / 1.64_{0}$ \\
\hline $5 d$ & $\mathrm{H}$ & mor & $\mathbf{H}$ & $\mathrm{NO}_{2}$ & $\mathrm{NO}_{2}$ & $8.773 / 8.822$ & $\begin{array}{l}7.134(2-\mathrm{H}) \\
\quad 6.924 / 6.987(3-\mathrm{H})\end{array}$ & & & $3.26_{0} / 3.21_{5}$ & $3.88_{5} / 3.78_{5}$ \\
\hline
\end{tabular}

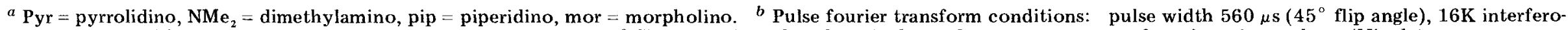
grams, spectral width $892.8571 \mathrm{~Hz} \simeq \pm 0.001 \mathrm{ppm}$ digital resolution. ${ }^{c}$ Shift data for other than singlet aryl proton spectra are from iterative analyses (Nicolet program ITRCL1/2, NIC 17-30712). $d$ Position of the intense center line of the individual characteristic $\mathrm{CH}_{2}$ multiplets. 
Table III. Long-Wavelength Absorption of the Donor-Acceptor Substituted Biphenyls 3 and 5 (in $\mathrm{CHCl}_{3}$, Ambient Temperature)

\begin{tabular}{|c|c|c|c|c|}
\hline compd & $\widetilde{\nu}_{\mathrm{cm}_{\text {max }}^{-1}}$ & $\lambda_{\mathrm{nm}} \lambda_{\max }$ & $\underset{\mathrm{Lmol}^{-1}}{\epsilon_{\max }}$ & $\Delta{\widetilde{v_{1 / 2}}}^{a} \mathrm{~cm}^{-1}$ \\
\hline $3 a$ & 17000 & 588 & 5800 & $5600(4200)$ \\
\hline $3 c$ & 18250 & 548 & 4400 & $6400(4600)$ \\
\hline $3 \mathbf{e}$ & 17600 & 568 & 7200 & $5700(4250)$ \\
\hline $3 f$ & 19200 & 521 & 4500 & $10600(4800)$ \\
\hline $3 g$ & 19100 & 524 & 6300 & $6200(4600)$ \\
\hline $3 \mathrm{~s}$ & 21900 & 457 & 6600 & $5900(5200)$ \\
\hline $3 \mathrm{i}$ & 20500 & 488 & 7500 & $5200(5200)$ \\
\hline $3 \mathrm{k}$ & 20500 & 487 & 7300 & 5500 \\
\hline $5 a$ & 19850 & 504 & 8100 & $5250(4500)$ \\
\hline $5 c$ & 21000 & 476 & 5200 & $7000(5400)$ \\
\hline $5 d$ & 22700 & 440 & 5100 & $6800(5200)$ \\
\hline
\end{tabular}

a The numerical values of $\Delta \tilde{\nu_{1 / 2}}$ are taken directly from the spectra. These data do not always present the true picture, though, since there are further electronic transitions in the region of the long-wavelength absorption, the number and intensity of which are both substituent dependent. The widths at half-height for the first electronic transition, given in parentheses, have been determined by a band analysis, based on the long-wavelength slope of the first absorption band.

$0.0725 \beta_{0}$ for $\mathrm{sp}^{3}$ hybridization of the $\mathrm{NR}_{2}$ nitrogen (with $280 \mathrm{pm}$ as a reasonable distance between $\mathrm{N}$ and $\mathrm{C}-1^{\prime}$ ).

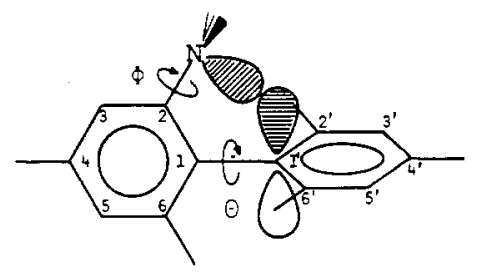$$
\begin{aligned}
& \theta=90^{\circ} \\
& \Phi=90^{\circ}
\end{aligned}
$$

(ii) The second process was interaction between an oxygen n-electron pair of an $o^{\prime}$-nitro group and the $\mathrm{p}_{z}$ orbitals at $\mathrm{C}-2$ and $\mathrm{C}-6$ in the donor arene. No additional rotation of the $\mathrm{NO}_{2}$ group relative to the plane of the acceptor arene (torsional angle $\Psi=0^{\circ}$ ) is required for this process. It likewise is ruled out by the negligible overlap integra ${ }^{9}$ and also for reasons of orbital symmetry.

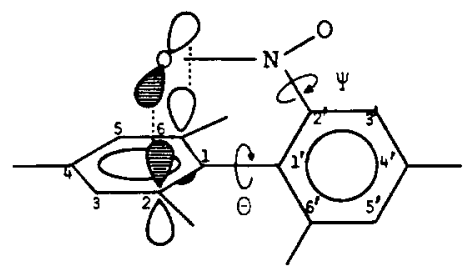

$$
\begin{aligned}
& \theta=90^{\circ} \\
& \Psi=0^{\circ}
\end{aligned}
$$

(iii) The third process was interaction of the $p_{2}$ orbitals of one arene with a pseudo- $\pi$ orbital of the other arene, made up from the " $\sigma$ " orbitals of the $\mathrm{C}-1 / \mathrm{C}-2$ and $\mathrm{C}-1 / \mathrm{C}-6$ or the $\mathrm{C}-1^{\prime} / \mathrm{C}-2^{\prime}$ and $\mathrm{C}-1^{\prime} / \mathrm{C}-6^{\prime}$ bonds, respectively. The large energy difference between the interacting orbitals eliminates such a straightforward intramolecular charge transfer between an electron-rich donor and an electrondeficient acceptor arene as the source of the long-wavelength absorption.

This leaves only a genuine $\pi^{-} \pi^{*}$ transition, polarized along the long molecular axis, as the origin of the deep color of the biphenyls 3 and 5 , such as one would expect for all nonorthogonal conformations $\left(\theta<90^{\circ}\right)$. Even with

(9) An overlap integral of $0.016 \beta_{0}$ is calculated between the oxygen $p$ orbital and the $\mathrm{p}_{2}$ lobes at C-2 and C-6 [with $r=260 \mathrm{pm}, \beta\left(\mathrm{p}_{\sigma}\right)=0.075 \beta_{0}$, and $\beta\left(p_{x}\right)=0.001 \beta_{0}$ as plausible limiting conditions].

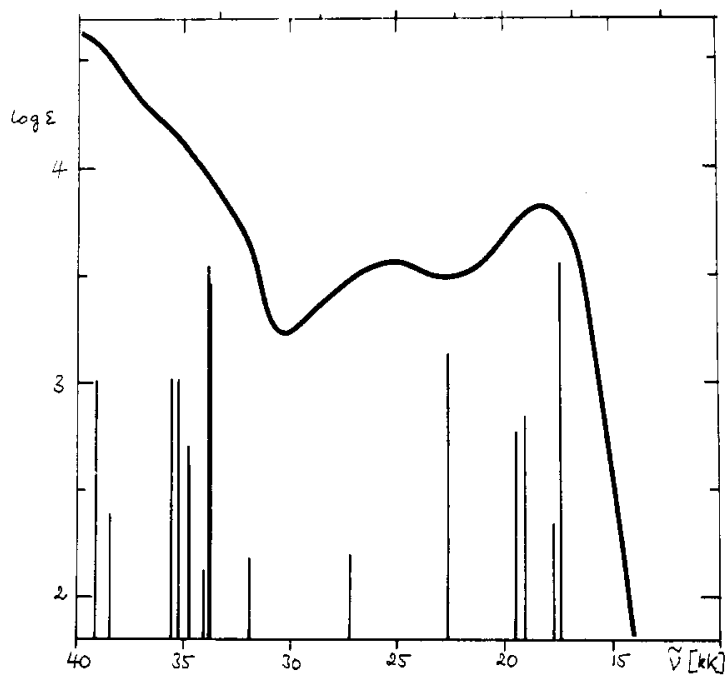

Figure 1. Absorption spectrum of 3a. The solid line represents the experimental spectrum in methylcyclohexane/isopentane (1:3) at ambient temperature. The calculated spectrum is presented as a stick spectrum (PPP calculation for a twisted geometry, with the torsional angles $\theta=52.5^{\circ}, \Phi=53.9^{\circ}$, and $\Psi=40.5^{\circ}$ from the X-ray structure analysis of $\mathbf{3 a}$ ).

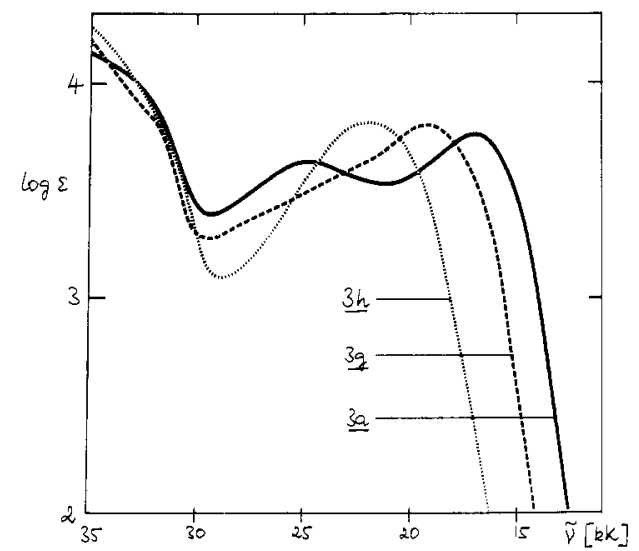

Figure 2. Dependence of the absorption spectra of 2,4,6-tripyrrolidinobiphenyls on the number of nitro groups in the $2^{\prime}-$, $4^{\prime}$-, and $6^{\prime}$-positions $\left(3 \mathrm{~h} \rightarrow 3 \mathrm{~g} \rightarrow 3 \mathrm{a}\right.$; in $\mathrm{CHCl}_{3}$, ambient temperature).

an $80^{\circ}$ torsion between the donor and acceptor $\pi$ systems, the effective overlap $\left(0.1736 \beta_{0}\right)$ is large compared with the overlap integrals calculated for the hypothetical mechanisms $i$ and ii. For "push-pull"-substituted biphenyls, the long-wavelength absorption thus represents an intramolecular CT transition by which electric charge is effectively transferred from the $\pi$-donor to the $\pi$-acceptor groups via the biaryl $\pi$ system.

The (hexasubstituted) biphenyls 3 , however, present some additional complexities compared to other, only 4,4'-disubstituted biaryls. Additional high-lying donor and low-lying acceptor terms are introduced into the molecules with the second and/or third $\pi$-donor and $\pi$-acceptor groups in the $2,2^{\prime}$ - and $6,6^{\prime}$-positions. This alone could explain the bathochromic band shift observed in going from $4,4^{\prime}$-di- to $2,2^{\prime}, 4,4^{\prime}, 6,6^{\prime}$-hexasubstituted biphenyl derivatives (see Table III and also the supplementary material).

At the same time, the steric interaction between the ortho substituents increases the torsion about the biphenyl linkage. For 4-amino-4'-nitrobiphenyl, a hypsochromic band shift is calculated with increasing torsional angle $\theta$. This effect is much attenuated for the higher substituted biphenyls 3 and 5; for 3a, even a slight bathochromic shift 
Table IV. Fractional Atomic Coordinates with Estimated Standard Deviations

\begin{tabular}{|c|c|c|c|c|c|c|c|}
\hline atom & $x$ & $y$ & $z$ & atom & $x$ & $y$ & $z$ \\
\hline $\mathrm{C} 11$ & $0.32748(7)$ & $0.25564(8)$ & $0.36815(6)$ & $\mathrm{O} 422$ & $0.71669(8)$ & $0.31535(9)$ & $0.4355(1)$ \\
\hline $\mathrm{C} 21$ & $0.28279(7)$ & $0.32875(8)$ & $0.33856(6)$ & N62 & $0.43398(7)$ & $0.10803(7)$ & $0.31537(6)$ \\
\hline $\mathrm{C} 31$ & $0.19623(7)$ & 0.32751 (8) & $0.33611(6)$ & 0621 & $0.46222(7)$ & $0.03051(7)$ & $0.32498(6)$ \\
\hline $\mathrm{C} 41$ & $0.15207(7)$ & $0.25185(8)$ & $0.36172(6)$ & 0622 & $0.38199(7)$ & $0.12752(7)$ & $0.27190(5)$ \\
\hline $\mathrm{C} 51$ & $0.19731(7)$ & $0.17696(8)$ & $0.38863(6)$ & H31 & $0.168(1)$ & $0.378(1)$ & $0.3148(9)$ \\
\hline C61 & $0.28371(7)$ & $0.17922(8)$ & $0.39285(6)$ & H51 & $0.169(1)$ & $0.123(1)$ & $0.4076(8)$ \\
\hline $\mathrm{C} 12$ & $0.41871(7)$ & $0.25784(8)$ & $0.37594(6)$ & $\mathrm{H} 32$ & $0.573(1)$ & $0.380(1)$ & $0.4419(9)$ \\
\hline $\mathrm{C} 22$ & $0.46340(8)$ & $0.32948(8)$ & $0.40736(6)$ & $\mathrm{H} 52$ & $0.586(1)$ & 0.124 (1) & $0.3536(9)$ \\
\hline $\mathrm{C} 32$ & $0.54896(8)$ & $0.32891(9)$ & $0.41893(7)$ & $\mathrm{H} 2111$ & $0.333(2)$ & $0.335(2)$ & $0.219(1)$ \\
\hline $\mathrm{C} 42$ & $0.59252(8)$ & $0.25166(9)$ & $0.39998(7)$ & $\mathrm{H} 2112$ & $0.420(1)$ & $0.342(2)$ & $0.259(1)$ \\
\hline $\mathrm{C} 52$ & $0.55407(8)$ & $0.17778(9)$ & $0.36814(7)$ & $\mathrm{H} 2121$ & $0.354(1)$ & $0.469(1)$ & $0.168(1)$ \\
\hline $\mathrm{C} 62$ & $0.46930(7)$ & $0.18385(8)$ & $0.35561(6)$ & $\mathrm{H} 2122$ & $0.446(1)$ & $0.479(2)$ & 0.204 (1) \\
\hline $\mathrm{N} 21$ & $0.32957(7)$ & $0.40130(7)$ & $0.31039(5)$ & $\mathrm{H} 2131$ & $0.334(1)$ & $0.596(1)$ & $0.2401(9)$ \\
\hline $\mathrm{C} 211$ & $0.3708(1)$ & $0.3779(1)$ & $0.24789(8)$ & $\mathrm{H} 2132$ & $0.404(1)$ & $0.562(1)$ & $0.294(1)$ \\
\hline C 212 & $0.38735(9)$ & $0.4697(1)$ & $0.21383(7)$ & $\mathrm{H} 2141$ & 0.280 & 0.520 & $0.342(1)$ \\
\hline $\mathrm{C} 213$ & $0.3565(1)$ & $0.54264(9)$ & $0.26208(8)$ & $\mathrm{H} 2142$ & $0.239(1)$ & $0.489(1)$ & $0.2715(9)$ \\
\hline $\mathrm{C} 214$ & $0.2902(1)$ & $0.49127(9)$ & $0.30018(8)$ & $\mathrm{H} 4111$ & $0.042(1)$ & $0.164(1)$ & $0.4369(9)$ \\
\hline $\mathrm{N} 41$ & $0.06726(7)$ & $0.25072(7)$ & $0.36074(6)$ & $\mathrm{H} 4112$ & $0.019(1)$ & $0.123(1)$ & $0.3675(9)$ \\
\hline C411 & $0.01843(8)$ & $0.17846(9)$ & $0.39194(7)$ & $\mathrm{H} 4121$ & $-0.073(1)$ & $0.254(1)$ & $0.4364(8)$ \\
\hline $\mathrm{C} 412$ & $-0.06888(8)$ & $0.2197(1)$ & $0.39549(7)$ & $\mathrm{H} 4122$ & $-0.113(1)$ & $0.173(1)$ & $0.392(1)$ \\
\hline C'413 & $-0.07198(8)$ & $0.2880(1)$ & $0.33809(7)$ & $\mathrm{H} 4131$ & $-0.080(1)$ & $0.255(1)$ & $0.2945(9)$ \\
\hline C414 & $0.01550(8)$ & $0.32905(8)$ & $0.34039(6)$ & $\mathrm{H} 4132$ & $-0.117(1)$ & $0.334(1)$ & $0.3444(9)$ \\
\hline N61 & $0.33093(6)$ & $0.10752(7)$ & $0.42324(5)$ & $\mathrm{H} 4141$ & $0.034(1)$ & $0.353(1)$ & $0.2967(8)$ \\
\hline C611 & $0.29855(8)$ & $0.01324(8)$ & $0.42119(6)$ & $\mathrm{H} 4142$ & $0.018(1)$ & $0.379(1)$ & $0.3713(8)$ \\
\hline $\mathrm{C} 612$ & $0.36016(8)$ & $-0.03715(8)$ & $0.46677(7)$ & H6111 & $0.300(1)$ & $-0.008(1)$ & $0.3769(8)$ \\
\hline C613 & $0.3722(1)$ & $0.0311(1)$ & $0.52364(7)$ & H6112 & $0.240(1)$ & $0.006(1)$ & $0.438(1)$ \\
\hline C 614 & $0.3641(1)$ & $0.12563(9)$ & $0.49120(7)$ & $\mathrm{H} 6121$ & $0.413(1)$ & $-0.047(1)$ & $0.443(1)$ \\
\hline $\mathrm{N} 22$ & $0.41990(7)$ & $0.41051 .(7)$ & $0.43411(6)$ & H6122 & $0.338(1)$ & $-0.095(1)$ & $0.481(1)$ \\
\hline 0221 & $0.35534(7)$ & $0.39794(7)$ & $0.46397(5)$ & $\mathrm{H} 6131$ & $0.327(2)$ & $0.023(2)$ & $0.556(1)$ \\
\hline 0222 & $0.45391(7)$ & $0.48557(7)$ & $0.42743(6)$ & $\mathrm{H} 6132$ & $0.426(1)$ & $0.026(1)$ & $0.547(1)$ \\
\hline $\mathrm{N} 42$ & $0.68294(8)$ & $0.24713(9)$ & $0.41207(7)$ & $\mathrm{H} 6141$ & $0.327(1)$ & $0.167(1)$ & $0.517(1)$ \\
\hline 0421 & $0.71924(7)$ & $0.17634(9)$ & $0.39771(8)$ & H6142 & $0.422(1)$ & $0.155(1)$ & $0.489(1)$ \\
\hline
\end{tabular}

with increasing $\theta$ is calculated. In addition to $\theta$, one has to consider the dihedral angle $\Phi$ between the $\pi$-symmetrical $o-\mathrm{N}$ donor orbital and the aminobenzene $\pi$ system and the dihedral angle $\Psi$ between the two $\pi$ systems of the 0 -nitro group and the acceptor benzene. A change even in one of these torsional angles will influence the experimental absorption in a complicated manner since $\theta, \Phi$, and $\Psi$ are mutually interdependent.

A calculation (PPP approximation) with the torsional angles from the crystal structure analysis of $3 \mathbf{a}, \theta=52.2^{\circ}$, $\Phi=53.9^{\circ}$, and $\Psi=40.5^{\circ}$, yields a spectrum which is in satisfactory agreement with the experimental absorption spectrum of $\mathbf{3 a}$ (Figure 1). The spectral band shifts observed within the series $3 a \rightarrow 3 g \rightarrow 3 h$ and $3 a \rightarrow 3 e \rightarrow 5 a$ (see Figures 2 and 3) are likewise reproduced satisfactorily by the calculation (excitation energies, oscillatory strengths, and polarization of the transitions for the individual compounds are given in the supplementary material).

All the biphenyls investigated consequently exist in a twisted, chiral conformation, with an energy minimum for $\theta<90^{\circ}$. Torsion about the $\mathrm{C}-1 / \mathrm{C}-1^{\prime}$ biphenyl linkage is best represented by a double minimum potential. The form of the potential, i.e., minimum potential position, energy difference $\Delta E$ between $E_{\min }$ and $E_{90^{\circ}}$, and steepness of the potential well, depends on the nature of the individual substituents and the respective torsional angles $\Phi$ and $\Psi$.

Only torsional, i.e., steric effects have been considered so far for the different biphenyl derivatives. The gradation of the broad long-wavelength absorption bands strikingly illustrates the hierarchy of the various $+\mathrm{M}$ substituents; their donor strength increases in the order $\mathrm{OCH}_{3}(\tilde{v} 29500$ (min $^{1}$ ) < morpholino < piperidino < pyrrolidino (see Table III). The bathochromic band shifts within the series $3 \mathrm{c}$ - 3a and $\mathbf{5 d}-5 \mathrm{c}-5 \mathrm{a}$ probably are due to increasingly higher lying donor terms. The larger band width and

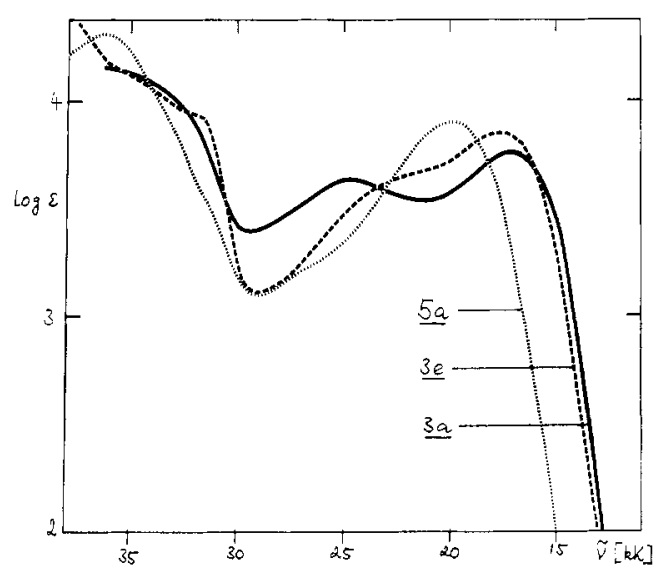

Figure 3. Dependence of the absorption spectra of $2^{\prime}, 4^{\prime}, 6^{\prime}$-trinitrobiphenyls on the number of pyrrolidino moieties in the 2-, 4 -, and 6-positions (5a $\rightarrow 3 \mathbf{e} \rightarrow 3 \mathbf{a}$; in $\mathrm{CHCl}_{3}$, ambient temperature).

reduced band integral of $3 \mathbf{c}$ relative to those of $3 \mathbf{a}$ can be interpreted in terms of greater steric demand of the piperidino relative to the pyrrolidino moiety.

\section{Crystal Structure Analysis of 3a}

The structure determination of $3 a$ reveals a conformation different from what might be expected for a biphenyl with four bulky ortho substituents. The torsion angle between the two aryl subunits, as determined by the angle between the normals of least-squares mean planes, fitted to the phenyl ring carbons, is $52.5^{\circ}$. Comparable values for perfluoro ${ }^{10 \mathrm{a}}$ and perchlorobiphenyl ${ }^{10 \mathrm{~b}}$ are $59.6^{\circ}$ and $86.6^{\circ}$, respectively. A stereoscopic projection of crystalline

(10) (a) Gleason, W. B.; Britton, D. Cryst. Struc. Commun. 1976, 5 483-488. (b) Pedersen, B. F. Acta Crystallogr., Sect. B 1975, B31, 2931-2933. 

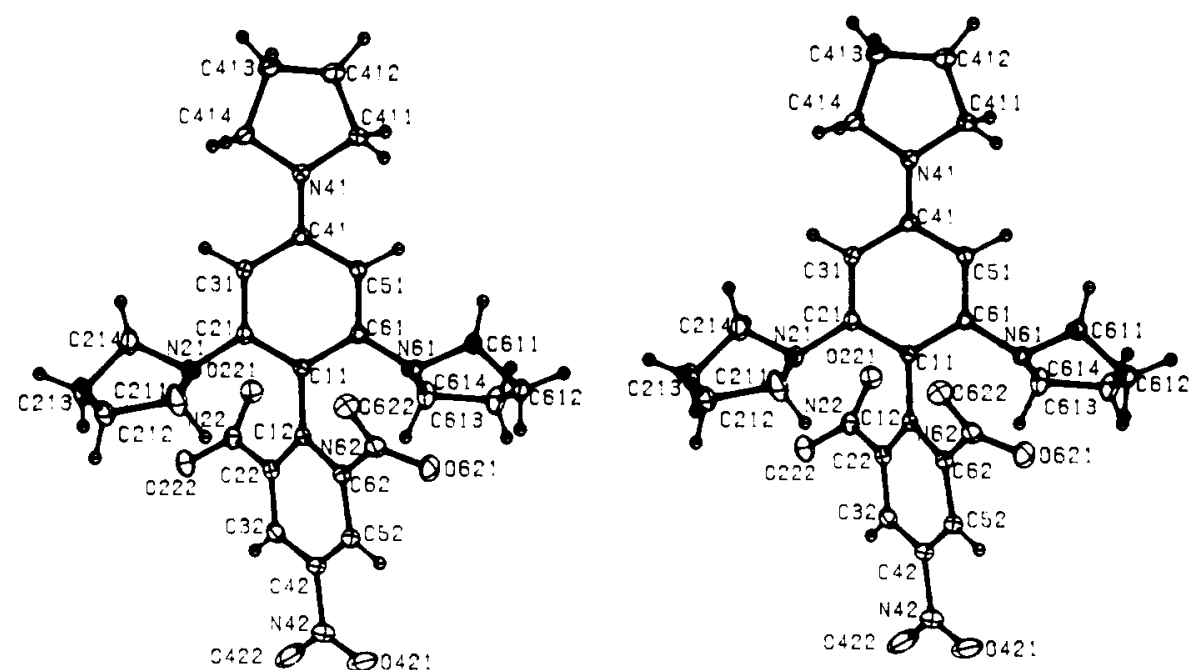

Figure 4. Stereoscopic projection ${ }^{13}$ of one molecule of $3 \mathbf{a}$.

Table V. Selected Bond Distances, ${ }^{a}$ Angles, and Dihedral Angles for 1-Methyl-2,4,6-tripyrrolidinobenzene (9) ${ }^{b}$

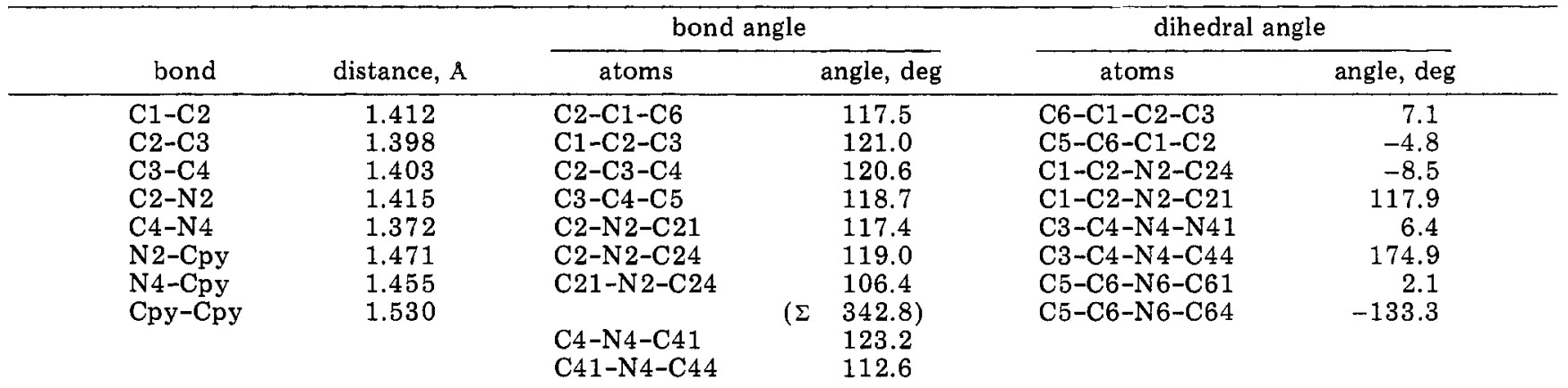

${ }^{a}$ Where appropriate, average values are given for bonds related by molecular, not crystallographic, symmetry. $b$ The locant numbering has been chosen to correspond to that for the biphenyls; correct name: 2-methyl-1,3,5-tripyrrolidinobenzene.

$3 \mathbf{a}$ is displayed in Figure 4 (for the refined fractional atomic coordinates see Table IV; for the bonding geometry see the supplementary material).

Each phenyl ring of $3 \mathbf{a}$, together with the respective substituents in 2,4,6-position, has approximate $C_{2}$ symmetry. The two local symmetry axes pass through the carbon and nitrogen atoms in positions 1 and 4; they differ from colinearity by $8.3^{\circ}$. The 0 -nitro groups are twisted by $40.5^{\circ}$ and the 0 -pyrrolidino groups by $53.9^{\circ}$ with respect to their parent arene rings; the corresponding average interplanar angles, on the other hand, for the $p$-pyrrolidino and $p-\mathrm{NO}_{2}$ substituents are only $5.4^{\circ}$ and $5.0^{\circ}$. The two phenyl rings which constitute the biphenyl 3a carry, respectively, strongly $\sigma$-electron-withdrawing substituents $\left(\mathrm{NO}_{2}\right)$ or substituents which are recognized as weak $\sigma$ but extremely good $\pi$ electron donors (pyrrolidino groups). ${ }^{5}$ In benzene derivatives, the deformation of the endocyclic bond angle of the substituted carbon atom (defined as $\alpha$ ) and the compensatory change in the endocyclic bond angles at the two adjacent carbon atoms $(\beta)$ have been correlated with the $\sigma$-electron-withdrawing or -releasing character of the individual substituents. ${ }^{11}$ Thus, a $\sigma-$ electron-donating substituent causes a decrease in $\alpha$ and an increase in $\beta$; for $\sigma$-electron-withdrawing groups, the opposite effect is observed. The magnitude of the angular deformation can be correlated, at least semiquantitatively, with the substituent group electronegativity. ${ }^{11}$ For substituents with the same electronegativity as the $\mathrm{C}_{6} \mathrm{H}_{6}$ ring,

(11) Domenicano, A.; Mazzeo, P.; Vaciago, A. Tetrahedron Lett. 1976, 1029-1032. and bonded by an atom of a first-row element, e.g., $\mathrm{CH}_{3}$, $\alpha$ has a standard value of $117.7^{\circ}$.

1-Methyl-2,4,6-tripyrrolidinobenzene (9) provides a suitable structural reference for the donor subunit of $\mathbf{3 a}$; relevant averaged bonding geometry parameters from a high precision structure determination of $9^{12}$ are summarized in Table V. The angle $\alpha$ at the methyl-substituted ring carbon $\mathrm{C}-1$ is $117.5^{\circ}$; this close-to-standard value demonstrates that the pyrrolidino groups in positions 2 , 4 , and 6 have no significant effect upon the endocyclic bond angle at C-1. So, from the bond angle $\alpha$ of $119.5^{\circ}$ established for the ring carbon atom $\mathrm{C}-1$ of $3 \mathrm{a}$, the $\sigma$ electron-withdrawal character of the trinitrophenyl moiety can be compared straightforwardly to that of $\mathrm{CONH}_{2}$ and $\mathrm{COOH}\left(\alpha 119.8^{\circ}\right)$ or that of $\mathrm{OCH}_{3}\left(\alpha 119.9^{\circ}\right)$. The respective angle $\alpha$ at $\mathrm{C}-1^{\prime}$ in the trinitrophenyl (acceptor) ring is $113.7^{\circ}$; this remarkable decrease, however, very likely contains a sizeable contribution from the two $\sigma$ electron-withdrawing $o$-nitro groups (decrease of $\beta$ ).

The clearly significant difference in inter-ring $\mathrm{C}-\mathrm{N}$ bond distances between $o$ - and $p$-pyrrolidino substituents is present in both 3a and 9 (see Tables IV and V); the effect thus must be primarily steric. No evidence for through conjugation between the two phenyl subunits can be gleaned from the structural data of the donor-acceptor substituted biphenyl 3a. The ${ }^{1} \mathrm{H}$ NMR data for the $p$ pyrrolidino functions likewise do not mirror the varying

(12) Schöllkopf, K. Diplomarbeit, Universität Stuttgart, 1979

(13) Johnson, C. K. "ORTEP-II", Technical Report ORNL-5138; Oak Ridge National Laboratory: Oak Ridge, TN, 1971. 
Table VI

\begin{tabular}{lccccc}
\hline atom & $U_{\mu \mu}$ & $Z_{\text {cor }}$ & $\gamma_{\mu \mu}$ & $\gamma_{\mu \nu}$ & $\beta_{\mu \nu}$ \\
\hline$-\mathrm{C}=$ & 0 & 1.0 & 9.0 & 5.1 & 1.0 \\
$-\mathrm{N}=$ & -3.0 & 1.0 & 9.6 & 5.2 & 1.05 \\
$-\mathrm{N}$ & -8.3 & 1.9 & 10.4 & 5.3 & 1.03 \\
$=\mathrm{O}$ & -4.9 & 1.0 & 11.2 & 6.4 & 1.25 \\
$=\mathrm{O}\left(\mathrm{NO}_{2}\right)$ & -4.9 & 1.0 & 11.2 & 5.8 & 1.0 \\
$-\mathrm{O}-$ & -14.8 & 2.0 & 12.6 & 6.2 & 1.05
\end{tabular}

electron demand of the different nitrophenyl acceptor rings.

\section{Experimental Section}

General Methods. ${ }^{1} \mathrm{H}$ NMR spectra were recorded on a Bruker HX-90-E, equipped with a 15 -in. magnet and a $20 \mathrm{~K}$ Nicolet BNC-12 computer, by use of the pulse Fourier transform technique at a $90.0-\mathrm{MHz}$ nominal frequency. The absorption spectra were measured with a Cary 118 and a Zeiss PMQ-3 spectrophotometer. Melting points were determined on a Büchi SMP-20 apparatus with a silicon bath and are uncorrected.

Calculations. The PPP calculations were performed with the approximations $\gamma_{\mu \nu}=9.6 / R_{\mu \nu}$ and $\beta_{\mu \nu}=0$ for nonadjacent centers $\mu$ and $\nu$. A $\beta$ correction was made with $\beta_{\mu \nu}=-2.05-0.7 p_{\mu \nu}(\mathrm{eV})$. A dielectric constant $\epsilon=0.913+0.0158 N$, dependent on the number, $N$, of centers, was used to account for the effect of molecular size on the respective parameters. The set of parameters $^{14}$ shown in Table VI was employed.

In the first iteration step ("Hückel calculation"), a set of parameters specially adopted for Hückel calculations always had to be used since otherwise the high number of electrons caused nonconvergency (a general result independent of the set of parameters used $\left.{ }^{14}\right)$. In the $\mathrm{CI}$ part, all single-excited configurations resulting from the six highest occupied and the five lowest unoccupied orbitals were considered.

All calculations were performed on the TR- 440 computer at Konstanz University Computer Center.

X-ray Structure Determination. A $0.5 \times 0.3 \times 0.3 \mathrm{~mm}^{3}$ single crystal in a thin-walled glass capillary was used for all X-ray diffraction measurements. The quantitative measurements were carried out with the crystal cooled to ca. $120 \mathrm{~K}$. The lattice parameters $[a=16.071$ (2) $\AA, b=14.545$ (1) $\AA, c=20.177$ (2) $\AA$, $\beta=91.361(9)^{\circ}$ ] were determined by a least-squares refinement ${ }^{15}$ with the $2 \theta$ values of 72 automatically centered reflections in the angular range $35.0^{\circ} \leq 2 \Theta \leq 45.5^{\circ}$. The space group is $C 2 / c$ with $Z=8$. Intensity data were measured with a Syntex P1 autodiffractometer equipped with a low-temperature device (Syntex LT-1). The scan range was $0.75^{\circ}$, the scan rate was $2.0-24.0^{\circ} / \mathrm{min}$, and background radiation was measured for half the total scan time on each side of the reflection $\left(\Delta \omega=1.0^{\circ}\right)$. Of the 14575 unique reflections measured $\left(2 \theta_{\max }=80.0^{\circ}, \lambda=0.71069 \AA\right), 6328$ were classified as observed under the criterion $I \geq 3.0 \sigma(I)$.

The initial structural model was determined by direct methods, with difficulties apparently resulting from pseudo face centering in the strongest $E$ values. The model was developed by difference Fourier and least-squares refinement techniques; all hydrogen atom coordinates were determined from difference electron density maps. The refinement of 437 variables (all atomic coordinates, anisotropic temperature factors for $\mathrm{C}, \mathrm{N}$, and $\mathrm{O}$ atoms, isotropic temperature factors for $\mathrm{H}$ atoms, and a single crystal factor) with 10825 contributing reflections converged to $R=0.054, R_{\mathrm{w}}=0.067$, and $\sigma=1.01$.

Starting Materials. 2-Chloro-5-nitro-1,3-benzenedicarboxylic Acid. 2-Chloroisophthalic acid ${ }^{16}(10.0 \mathrm{~g}, 49.8 \mathrm{mmol})$ was added in small portions at $20^{\circ} \mathrm{C}$ to a stirred mixture of fuming nitric acid $(51 \mathrm{~mL})$ and $45 \%$ oleum $(56.5 \mathrm{~mol})$ and refluxed for $6 \mathrm{~h}$. The cooled mixture was poured on ice, and the colorless

(14) Kollmannsberger-von Nell, G., unpublished results

(15) Stewart, J. M.; Machin, P. A.; Dickinson, C. W.; Ammon, H. L.; Flack, H.; Heck, H. “The XRAY System Version 1976", Technical Report TR-446; University of Maryland Computer Science Center: College Park, MD, 1976. Unless otherwise indicated, this program was used for all computerized calculations.

(16) Stapleton, G.; White, A. I. J. Am. Pharm. Assoc. 1954, 43, 193200; Chem. Abstr. 1955, 49, $8968 b$. precipitate was separated by filtration, and recrystallized from water or ethanol: yield $10.5 \mathrm{~g}(86 \%) ; \mathrm{mp} 187^{\circ} \mathrm{C}$. Anal. Calcd for $\mathrm{C}_{8} \mathrm{H}_{4} \mathrm{ClNO}_{6}\left(M_{\mathrm{r}}=245.6\right): \mathrm{C}, 39.12 ; \mathrm{H}, 1.64 ; \mathrm{Cl}, 14.43 ; \mathrm{N}, 5.70$. Found: $\mathrm{C}, 38.93 ; \mathrm{H}, 1.75 ; \mathrm{Cl}, 14.42 ; \mathrm{N}, 5.48$.

Dimethyl 2-Chloro-5-nitro-1,3-benzenedicarboxylate (2f). Dry hydrogen chloride was passed through a stirred solution of 2-chloro-5-nitro-1,3-benzenedicarboxylic acid $(9.8 \mathrm{~g}, 40.0 \mathrm{mmol})$ in absolute methanol $(50 \mathrm{~mL})$ for $2 \mathrm{~h}$; in the course of the exothermic reaction, the solution heated up to the boiling point. The solvent was stripped off, and the residue was taken up in water and, after basification with sodium carbonate, extracted with ether. The extract was dried over sodium sulfate and evaporated to dryness, and the residue was recrystallized from petroleum ether (bp $80-120^{\circ} \mathrm{C}$ ) to give $2 \mathrm{f}: 9.58 \mathrm{~g}(88 \%) ; \mathrm{mp} 100^{\circ} \mathrm{C}$. Anal. Calcd for $\mathrm{C}_{10} \mathrm{H}_{8} \mathrm{ClNO}_{6}\left(M_{\mathrm{r}}=237.6\right) ; \mathrm{C}, 43.89 ; \mathrm{H}, 2.94 ; \mathrm{Cl}, 12.95 ; \mathrm{N}, 5.11$. Found: C, 43.67; H, 3.63; Cl, 12.88; N, 5.31.

4-Iodopyrrolidinobenzene (4a). 1,4-Dibromobutane (4.31 $\mathrm{g}, 20.0 \mathrm{mmol}$ ) was added at room temperature to a stirred solution of 4-iodoaniline $(4.38 \mathrm{~g}, 20.2 \mathrm{mmol})$ in benzene $(10 \mathrm{~mL})$ and $N, N$-diisopropylethylamine $(5.16 \mathrm{~g}, 39.9 \mathrm{mmol})$. The reaction mixture was heated to $50^{\circ} \mathrm{C}$ for $24 \mathrm{~h}$, and the cooled suspension was filtered. The filter cake was washed with $2 \mathrm{~N} \mathrm{NaOH}$ and recrystallized from ethanol, yielding 4a: $4.43 \mathrm{~g} \mathrm{(81 \% );} \mathrm{mp} 108$ ${ }^{\circ} \mathrm{C}$. Anal. Calcd for $\mathrm{C}_{10} \mathrm{H}_{12} \mathrm{IN}\left(M_{\mathrm{r}}=273.1\right)$ : C, 43.97; H, 4.42; I, 46.47; N, 5.13. Found: C, 44.26; H, 4.64; I, 46.24; N, 4.97. 4-Iodopiperidinobenzene (4c). 4-Iodoaniline (4.38 g, 20.2 $\mathrm{mmol})$ in benzene $(10 \mathrm{~mL}), N, N$-diisopropylethylamine $(5.16 \mathrm{~g}$ $39.9 \mathrm{mmol})$, and 1,5-dibromopentane $(4.60 \mathrm{~g}, 20.0 \mathrm{mmol})$ were treated as above to give $4 \mathrm{~b}: 2.67 \mathrm{~g}(46 \%) ; \mathrm{mp} 77^{\circ} \mathrm{C}$. Anal. Calcd for $\mathrm{C}_{11} \mathrm{H}_{14} \mathrm{IN}\left(M_{\mathrm{r}}=287.1\right)$ : C, 46.01; $\mathrm{H}, 4.91 ; \mathrm{I}, 44.20 ; \mathrm{N}, 4.88$. Found: C, $46.21 ; \mathrm{H}, 4.97$; I, 44.25; N, 5.07.

4-Iodomorpholinobenzene (4d). Finely powdered iodine $(10.15 \mathrm{~g}, 40.0 \mathrm{mmol})$ was added slowly at $12-15^{\circ} \mathrm{C}$ to a stirred mixture of morpholinobenzene $\mathrm{e}^{17}(6.25 \mathrm{~g}, 38.3 \mathrm{mmol})$ and sodium bicarbonate $(5.04 \mathrm{~g}, 60.0 \mathrm{mmol})$ in water $(50 \mathrm{~mL})$. Stirring was continued at room temperature for $1 \mathrm{~h}$, the dark solid separated by filtration and dissolved in ethanol, and the filtrate was discolored with an aqueous solution of sodium thiosulfate. 4d was precipitated with water, and recrystallized from ethanol: 3.64 g $(32 \%) ; m p 146^{\circ} \mathrm{C}$. Anal. Calcd for $\mathrm{C}_{10} \mathrm{H}_{12} \mathrm{INO}\left(M_{\mathrm{r}}=289.1\right)$ : C, 41.54; H, 4.18; I, 43.89; N, 4.84. Found: C, 41.53; H, 4.22; I, $44.03 ; \mathrm{N}, 4.85$.

2,4,6-Tripiperidinoiodobenzene (6c). To a stirred mixture of 1,3,5-tripiperidinobenzene $\left(1 \mathrm{c},{ }^{18} 1.64 \mathrm{~g}, 5.0 \mathrm{mmol}\right)$ in methylene chloride $(10 \mathrm{~mL})$ and finely powdered sodium bicarbonate $(1.26$ $\mathrm{g}, 15.0 \mathrm{mmol}$ ) was added dropwise a solution of iodine chloride $(0.81 \mathrm{~g}, 5.0 \mathrm{mmol})$ in methylene chloride $(5 \mathrm{~mL})$ at room temperature (the mixture heated to the boiling point). Methanol (5 $\mathrm{mL}$ ) was added, stirring continued for $1 \mathrm{~h}$ at $40^{\circ} \mathrm{C}$, the reaction mixture filtered, and the filtrate evaporated to dryness. The brown-red residue was washed with water, purified by successive chromatography on silica gel (column $15 \mathrm{~cm} \times 2 \mathrm{~cm}$ o.d.) and Merck Nr. 9385 silica gel (column $50 \mathrm{~cm} \times 4 \mathrm{~cm}$ o.d.) with ethyl acetate $(22 \mathrm{~mL} / \mathrm{min})$ as the eluent. First fraction: $6 \mathrm{c}, 0.4 \mathrm{~g}(18 \%)$; mp $146^{\circ} \mathrm{C}$. Anal. Calcd. for $\mathrm{C}_{21} \mathrm{H}_{32} \mathrm{IN}_{3}\left(M_{\mathrm{r}} 453.4\right)$ : C, $55.63 ; \mathrm{H}$ 7.11; I, 27.99; N, 9.27. Found: C, 55.53; H, 7.21; I, 27.80; N, 9.20 . Second fraction: $1 \mathrm{c}, 0.58 \mathrm{~g} ; \mathrm{mp} 183^{\circ} \mathrm{C}$ (ref. ${ }^{17} \mathrm{mp} 183-184^{\circ} \mathrm{C}$ ).

2,4,6-Trimorpholinoiodobenzene (6d). 1,3,5-Trimorpholinobenzene $\left(1 \mathrm{~d}^{18} 1.66 \mathrm{~g}, 5.0 \mathrm{mmol}\right)$, iodine chloride $(0.81$ $\mathrm{g}, 5.0 \mathrm{mmol}$ ), and sodium bicarbonate $(1.26 \mathrm{~g}, 15.0 \mathrm{mmol})$ were reacted as described above. The crude product was recrystallized repeatedly from acetone/methanol (6:4) to give $6 \mathrm{~d}: 0.82 \mathrm{~g} \mathrm{(36 \% );}$ mp $256^{\circ} \mathrm{C}$. Anal. Calcd for $\mathrm{C}_{18} \mathrm{H}_{26} \mathrm{IN}_{3} \mathrm{O}_{3}\left(M_{\mathrm{r}}=459.3\right)$ : C, 47.07; H, 5.70; I, 27.63; N, 9.15. Found: C, 47.61; H, 5.81; I, 27.59; N, 8.87 .

Biphenyls 3 (Tables I and VII). General Procedure. A solution of the 4-halonitrobenzene 2 in ethanol was added to a boiling solution of the aminobenzene 1 in chloroform, and the resulting dark red mixture was refluxed for $4 \mathrm{~h}$. The solvents were evaporated, and the residue was dissolved in boiling ethanol. When the mixture cooled to room temperature, the product precipitated. The dark red crystals were filtered off and purified

(17) Shono, T.; Iikuni, T.; Oda, R. Nippon Kagaku Zasshi 1960, 81, 1625; Chem Abstr, 1962, 56, 7188c.

(18) Effenberger, F.; Niess, R. Chem. Ber. 1968, 101, 3787-3793. 
Table VII. Biphenyls 3 from Aminobenzenes 1 and 4-Halonitrobenzenes $2^{d, e}$

\begin{tabular}{|c|c|c|c|c|c|}
\hline $\begin{array}{l}\text { aminobenzene } \\
(\mathrm{g}, \mathrm{mmol})\end{array}$ & $\begin{array}{c}\text { in } \mathrm{CHCl}_{3} \text {, } \\
\mathrm{mL}\end{array}$ & $\begin{array}{l}\text { 4-halonitrobenzene } \\
\text { (g, mmol) }\end{array}$ & $\begin{array}{l}\text { in } \mathrm{EtOH}, \\
\mathrm{mL}\end{array}$ & $\begin{array}{l}\text { biphenyl } \\
\text { (yield, g) }\end{array}$ & recrystallized from ${ }^{a}$ \\
\hline $\begin{array}{l}1 \mathrm{a}^{18}(5.71,20.0) \\
1 \mathrm{c}^{18}(6.55,20.0) \\
1 \mathrm{~d}^{18}(6.66,19.9) \\
1 \mathrm{e}^{21}(4.32,20.0) \\
1 \mathrm{f}^{21}(4.88,20.0)\end{array}$ & $\begin{array}{l}15 \\
15 \\
30 \\
15 \\
15\end{array}$ & $\begin{array}{l}2 \mathrm{a}(2.47,10.0) \\
2 \mathrm{a}(2.47) \\
2 \mathrm{a}(2.47) \\
2 \mathrm{a}(2.47) \\
\mathrm{2a}(2.47)\end{array}$ & $\begin{array}{l}15 \\
15 \\
15 \\
15 \\
15\end{array}$ & $\begin{array}{l}3 \mathrm{a}(3.77) \\
3 \mathrm{c}(3.82) \\
3 \mathrm{~d}(3.7) \\
3 \mathrm{e}(3.16) \\
\mathbf{3 f}^{b, c}(2.96)\end{array}$ & $\begin{array}{l}\text { EtOH/PE }(7: 3) \\
\text { EtOH/PE/C } / \mathrm{C}_{6}(6: 2: 2) \\
\text { EtOH/C } / \mathrm{C}_{6}(7: 3) \\
\text { EtOH/PE }(7: 3) \\
\text { EtOH/C } / \mathrm{C}_{6} / \mathrm{CH}_{2} \mathrm{Cl}_{2} \\
\quad(6: 2: 2)\end{array}$ \\
\hline $\begin{array}{l}\text { 1a }(5.71) \\
\text { 1a }(5.71) \\
\text { 1a }(5.71) \\
\text { 1a }(5.71) \\
\text { 1a }(5.71) \\
\text { 1a }(1.427,5.0) \\
\text { 1a }(2.85,10.0) \\
\text { 1e }(28.0,129.4)\end{array}$ & $\begin{array}{r}15 \\
15 \\
15 \\
15 \\
15 \\
7 \\
7 \\
60\end{array}$ & $\begin{array}{l}\text { 2b }(2.02,10.0) \\
2 \mathrm{~d}(1.82,10.0) \\
2 \mathrm{e}(2.15,10.0) \\
2 \mathrm{e}^{\prime}(1.99,10.0) \\
2 \mathrm{f}(2.73,10.0) \\
2 \mathrm{~g}(1.302,5.0) \\
2 \mathrm{~h}(1.57,6.9) \\
2 \mathrm{~g}(14.0,53.7)\end{array}$ & $\begin{array}{r}15 \\
15 \\
15 \\
15 \\
15 \\
5 \\
5 \\
60\end{array}$ & $\begin{array}{l}\text { 3g (3.34) } \\
\text { 3i }(2.61) \\
\text { 3k }(2.2) \\
\text { 3k }(4.01) \\
\text { 3l }(4.07) \\
\text { 3m }(0.55) \\
\text { 3n }(1.26) \\
\text { 3o }(20.0)\end{array}$ & $\begin{array}{l}\text { EtOH/PE }(8: 2) \\
\text { EtOH/PE }(8: 2) \\
\text { EtOH/C } \mathrm{C}_{6}(8: 2) \\
\text { EtOH/PE }(8: 2) \\
\text { EtOH } \\
\text { EtOH/C } \mathrm{H}_{6}(4: 1) \\
\text { EtOH/PE }(8: 2)\end{array}$ \\
\hline
\end{tabular}

${ }^{a} \mathrm{PE}=$ petroleum ether. ${ }^{b}$ After $12 \mathrm{~h}$ of refluxing. ${ }^{c}$ In a second preparation, $2 \mathrm{a}(0.62 \mathrm{~g}, 2.5 \mathrm{mmol})$ in ethanol $(5 \mathrm{~mL})$ was added to $1 \mathrm{f}(1.08 \mathrm{~g}, 4.5 \mathrm{mmol})$ in chloroform $(10.0 \mathrm{~g})$ at $70^{\circ} \mathrm{C}$. The mixture was refluxed for $10 \mathrm{~min}$. Ethanol $(50$ $\mathrm{mL}$ ) was added, the reaction mixture cooled to $0{ }^{\circ} \mathrm{C}$, and the precipitate recrystallized from ethanol; yield $0.82 \mathrm{~g}(72 \%)$ of 3f as black crystals, $\mathrm{mp} 179^{\circ} \mathrm{C}$. $d$ Satisfactory analytical data $( \pm 0.3 \%$ for $\mathrm{C}, \mathrm{H}, \mathrm{N})$ for all biphenyls (except as noted) were submitted for review. Exception: 3f, calcd for $\mathrm{C}_{22} \mathrm{H}_{25} \mathrm{~N}_{5} \mathrm{O}_{6}$ : C, 58.01; H, 5.53; N, 15.38. Found: C, 58.55; H, 5.38; N, 14.86. $e$ For yields and melting points, see Table I.

by recrystallization (see Table VII).

2,4,6-Tris(dimethylamino)-2', $4^{\prime}, 6^{\prime}$-trinitrobiphenyl (3b). A solution of $1,3,5$-tris(dimethylamino) benzene $\left(1 \mathrm{~b} ;{ }^{18} 4.34 \mathrm{~g}, 20.9\right.$ $\mathrm{mmol})$ in chloroform $(25 \mathrm{~mL})$ was added to a solution of $2 \mathrm{a}(2.47$ g, $10.0 \mathrm{mmol})$ in ethanol $(25 \mathrm{~mL})$. The resulting dark red solution was refluxed for $10 \mathrm{~min}$ and allowed to cool to room temperature, and the precipitate was separated by filtration and recrystallized from benzene/ethanol (1:3) to give $3 \mathrm{~b}: 2.5 \mathrm{~g}(60 \%)$; $\mathrm{mp} 258^{\circ} \mathrm{C}$. Anal. Calcd for $\mathrm{C}_{18} \mathrm{H}_{22} \mathrm{~N}_{6} \mathrm{O}_{6}\left(M_{\mathrm{r}}=418.4\right)$ : C, 51.67; $\mathrm{H}, 5.30 ; \mathrm{N}$, 20.09. Found: C, 51.88, H, 54.1; N, 19.94.

2,4,6-Tripyrrolidino-4 $4^{\prime}$-nitrobiphenyl (3h). Compound la $(5.71 \mathrm{~g}, 20.0 \mathrm{mmol})$ and 4-fluoronitrobenzene $\left(2 \mathrm{c}^{\prime} ; 1.41 \mathrm{~g}, 10.0\right.$ mmol) were heated in a sealed tube to $120^{\circ} \mathrm{C}$ for $20 \mathrm{~h}$. The dark reaction mixture was taken up in hot methylene chloride, the solvent evaporated, and the dark residue recrystallized from ethyl acetate/ethanol. The red precipitate was recrystallized from cyclohexene to give $3 \mathrm{~h}: 0.54 \mathrm{~g}(13 \%) ; \mathrm{mp} 236^{\circ} \mathrm{C}$. Anal. Calcd for $\mathrm{C}_{24} \mathrm{H}_{30} \mathrm{~N}_{4} \mathrm{O}_{2}\left(M_{\mathrm{r}}=406.5\right)$ : C, $70.91 ; \mathrm{H}, 7.44 ; \mathrm{N}, 13.78$. Found: C, $70.43 ; \mathrm{H}, 7.22 ; \mathrm{N}, 13.35$.

Ullmann Reactions for the Preparation of 4-Amino$2^{\prime}, 4^{\prime}, 6^{\prime}$-trinitrobiphenyls 5. General Procedure. A mixture of 1,3,5-trinitrobenzene $(2.13 \mathrm{~g}, 10.0 \mathrm{mmol})$, 4-iodoaminobenzene $4(10.0 \mathrm{mmol})$, and $\mathrm{Cu}_{2} \mathrm{O}(0.72 \mathrm{~g}, 5.0 \mathrm{mmol})$ in absolute quinoline $(25 \mathrm{~mL})$ was slowly heated to $180^{\circ} \mathrm{C}$ with vigorous stirring and kept at $180^{\circ} \mathrm{C}$ for $1 \mathrm{~h}$. After the mixture cooled to room temperature, $200 \mathrm{~mL}$ of ether was added, the resulting suspension was filtered, and the yellow filter cake was carefully washed with ether. The ether was evaporated to dryness, and the resulting deep red oily residue was purified by chromatography on silica gel (column $50 \mathrm{~cm} \times 1.5 \mathrm{~cm}$ o.d., eluent benzene). The red fraction was evaporated and the residue recrystallized from methylene chloride/cyclohexane.

4-Pyrrolidino-2', $4^{\prime}, 6^{\prime}$-trinitrobiphenyl (5a). Reaction with $4 \mathrm{a}(2.73 \mathrm{~g})$ yielded 5a: $0.86 \mathrm{~g}(24 \%) ; \mathrm{mp} 205^{\circ} \mathrm{C}$. Anal. Calcd for $\mathrm{C}_{16} \mathrm{H}_{16} \mathrm{H}_{4} \mathrm{O}_{6}\left(M_{\mathrm{r}}=358.3\right)$ : $\mathrm{C}, 53.63 ; \mathrm{H}, 3.94 ; \mathrm{N}, 15.64$. Found: C, 54.14; H, 3.79; N, 15.67 .

4-Piperidino-2', $4^{\prime}, 6^{\prime}$-trinitrobiphenyl (5c). Reaction with $4 \mathrm{c}(2.87 \mathrm{~g})$ yielded $5 \mathrm{c}: 0.48 \mathrm{~g}(13 \%) ; \mathrm{mp} 152^{\circ} \mathrm{C}$. Anal. Calcd for $\mathrm{C}_{17} \mathrm{H}_{16} \mathrm{~N}_{4} \mathrm{O}_{6}\left(M_{\mathrm{r}}=372.3\right)$ : $\mathrm{C}, 54.84 ; \mathrm{H}, 4.33 ; \mathrm{N}, 15.05$. Found: C, 54.84; H, 4.40; N, 15.28.

4-Morpholino-2', $4^{\prime}, 6^{\prime}$-trinitrobiphenyl (5d). Reaction with 4d $(2.89 \mathrm{~g})$ yielded $5 \mathrm{~d}: 0.42 \mathrm{~g}(11 \%) ; \mathrm{mp} 245^{\circ} \mathrm{C}$. Anal. Calcd for $\mathrm{C}_{16} \mathrm{H}_{14} \mathrm{~N}_{4} \mathrm{O}_{7}\left(M_{\mathrm{r}}=374.3\right)$ : $\mathrm{C}, 51.34 ; \mathrm{H}, 3.77 ; \mathrm{N}, 14.97$. Found: C, 51.40; H, 3.75; N, 14.96.

Reaction of $6 \mathrm{c}$ with 4-Iodonitrobenzene. A stirred mixture of 4-iodonitrobenzene $(1.24 \mathrm{~g}, 5.0 \mathrm{mmol}), 6 \mathrm{c}(2.26 \mathrm{~g}, 5.0 \mathrm{mmol})$, and activated copper ( $1.5 \mathrm{~g}$, see below) was heated slowly to 250 ${ }^{\circ} \mathrm{C}$ and kept at this temperature for $1 \mathrm{~h}$. After cooling to room temperature, the reaction mixture was extracted repeatedly with methylene chloride. The dark extract was washed several times with aqueous hydrochloride acid, and the organic layer was evaporated to dryness, taken up with a little warm benzene, filtered, and kept at room temperature; after 2 days, $0.114 \mathrm{~g}$ of $4,4^{\prime}$-dinitrobiphenyl (8) was isolated by filtration: $\mathrm{mmp} 235^{\circ} \mathrm{C}$ (lit. ${ }^{19} \mathrm{mp} 237^{\circ} \mathrm{C}$ ). The aqueous phase was made basic with $2 \mathrm{~N}$ $\mathrm{NaOH}$ and extracted with methylene chloride. The methylene chloride was stripped off and the gray residue treated with methanol to give lc $\left[82 \mathrm{mg}\right.$; mmp $181^{\circ} \mathrm{C}$ (lit. $\left.\left..^{18} \mathrm{mp} 183-184^{\circ} \mathrm{C}\right)\right]$ and $132 \mathrm{mg}$ of $2,2^{\prime}, 4,4^{\prime}, 6,6^{\prime}$-hexapiperidinobiphenyl (7c), $\mathrm{mmp} 318$ ${ }^{\circ} \mathrm{C}$ (lit. ${ }^{20} \mathrm{mp} 320-322^{\circ} \mathrm{C}$ ).

The activated copper was prepared by treating copper with a $2 \%$ solution of iodine in acetone for $10 \mathrm{~min}$. After filtration, the residue was treated with a mixture of hydrochloric acid and acetone. The activated copper was filtered off, washed carefully with acetone, dried in vacuo, and used immediately.

In a second preparation, a mixture of 4 -iodonitrobenzene $(1.24$ g, $5.0 \mathrm{mmol}), 6 \mathrm{c}(2.26 \mathrm{~g}, 5.0 \mathrm{mmol}), \mathrm{Cu}_{2} \mathrm{O}(0.72 \mathrm{~g}, 5.0 \mathrm{mmol})$, and quinoline $(25 \mathrm{~mL})$ was heated slowly with stirring to $180^{\circ} \mathrm{C}$ and kept at $180^{\circ} \mathrm{C}$ for $1 \mathrm{~h}$. Quinoline was distilled off, and the residue repeatedly extracted with warm methylene chloride. The extracts were filtered and concentrated, the dark oily residue was treated with aqueous hydrochloric acid, and the resulting solution was filtered, made basic $(2 \mathrm{~N} \mathrm{NaOH})$, and extracted with chloroform. Evaporation of the chloroform phase yielded a gray product $(600$ $\mathrm{mg}$ ), which was identified as a mixture of $1 \mathrm{c}$ and $7 \mathrm{c}$ by ${ }^{1} \mathrm{H}$ NMR and TLC.

Reaction of $6 \mathrm{~d}$ with 4-Iodonitrobenzene. 4-Iodonitrobenzene $(1.24 \mathrm{~g}, 5.0 \mathrm{mmol}), 6 \mathrm{~d}(2.29 \mathrm{~g}, 5.0 \mathrm{mmol})$, and activated copper $(1.5 \mathrm{~g})$ were treated as above. The methylene chloride extract yielded $80 \mathrm{mg}$ of $8, \mathrm{mmp} 235^{\circ} \mathrm{C}$, (lit..$^{19} \mathrm{mmp} 237^{\circ} \mathrm{C}$ ). From the aqueous phase, $384 \mathrm{mg}$ of a gray solid were obtained which yielded, after repeated treatment with chloroform, $1 \mathrm{~d}$ [130 $\mathrm{mg} ; \mathrm{mp} 308$ ${ }^{\circ} \mathrm{C}$ (lit. ${ }^{18} \mathrm{mp} \mathrm{308-312}{ }^{\circ} \mathrm{C}$ )] and $254 \mathrm{mg}$ of $2,2^{\prime}, 4,4^{\prime}, 6,6^{\prime}$-hexamorpholinobiphenyl (7d), mmp $334{ }^{\circ} \mathrm{C}$ (lit. ${ }^{20} \mathrm{mp} 344-346^{\circ} \mathrm{C}$ ).

Registry No. 1a, 16857-93-5; 1b, 16857-99-1; 1c, 16857-95-7; 1d, 16857-97-9; le, 27594-18-9; 1f, 27594-19-0; 2a, 88-88-0; 2b,

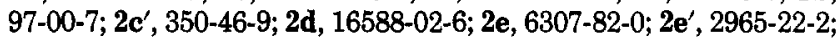
2f, 87350-69-4; 2g, 2213-79-8; 2h, 27697-45-6; 3a, 33931-06-5; 3b, 87350-70-7; 3c, 87350-71-8; 3d, 87350-72-9; 3e, 33949-03-0; 3f, 87350-73-0; 3g, 33949-02-9; 3h, 87350-74-1; 3i, 33949-06-3; 3k, 87370-87-4; 31, 87350-75-2; 3m, 33949-04-1; 3n, 33931-07-6; 3o, 33931-13-4; 4a, 87350-76-3; 4c, 55376-34-6; 4d, 87350-77-4; 5a, 87350-78-5; 5c, 87350-79-6; 5d, 87350-80-9; 6c, 87350-81-0; 6d, 87350-82-1; 2-chloro-5-nitro-1,3-benzenedicarboxylic acid,

(19) Ullmann, F.; Frentzel, L. Ber. Dtsch. Chem. Ges. 1905, 38, $725-729$.

(20) (a) Effenberger, F.; Stohrer, W. D.; Steinbach, A. Angew. Chem. 1969, 81, 261-262; Angew. Chem., Int. Ed. Engl. 1969, 8, 280. (b) Steinbach, A. Dissertation, Universität Stuttgart, 1969, pp 230, 233.

(21) Effenberger, F.; Prossel, G.; Auer, E.; Fischer, P. Chem. Ber, 1970, 103, 1456-1462. 
87350-83-2; 2-chloroisophthalic acid, 13049-16-6; 1,4-dibromobutane, 110-52-1; 4-iodoaniline, 540-37-4; 1,5-dibromopentane, 111-24-0; morpholinobenzene, 92-53-5; 1,3,5-trinitrobenzene, 9935-4; 4-iodonitrobenzene, 636-98-6.

Supplementary Material Available: Figure 5a-c with the bonding geometry of $3 \mathrm{a}$ (selected bond distances, bond angles, and dihedral angles), tabulated calculated and observed structure factors, and Table VIII, listing the results of the PPP calculations for 4-(dialkylamino)-4'-nitrobiphenyl and for the (dialkylamino)nitrobiphenyls $\mathbf{3 a}, \mathbf{e}, \mathbf{g}, \mathbf{h}$ and $\mathbf{5 a}$ [excitation energies ( $\tilde{\nu}$, $\lambda)$, oscillatory strengths, and polarizations $\left(\mu_{x}, \mu_{y}, \mu_{z}\right)$ are given for the individual electronic transitions] (95 pages). Ordering information is given on any current masthead page. 